
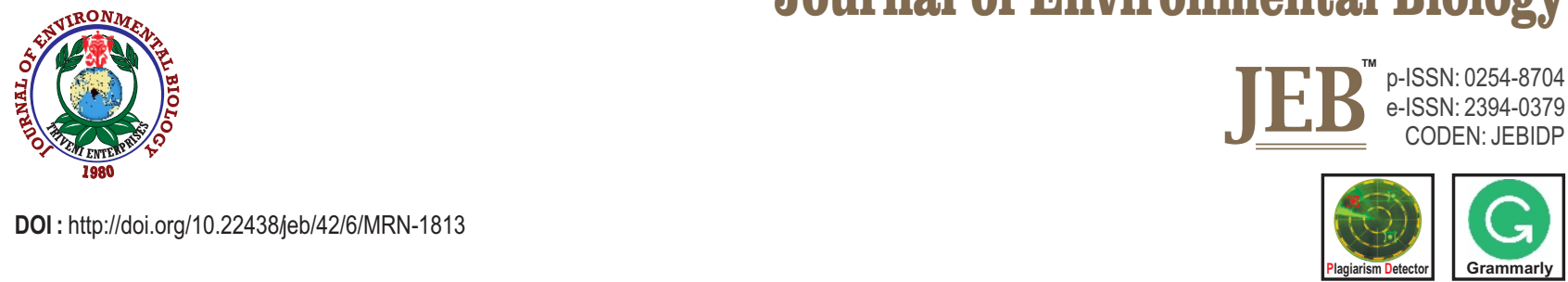

\title{
Evaluation of bunch quality components in Dura $x$ Dura progenies of Zambia and Camaroon sources of oil palm germplasm
}

\author{
A. Pedapati', R.K. Mathur', G. Ravichandran', B.K. Babu ${ }^{2}$ and H.P. Bhagya ${ }^{2}$ \\ 'ICAR-Indian Institute of Oil Palm Research, Pedavegi-534450, India \\ ${ }^{2}$ Crop Improvement, ICAR-Indian Institute of Oil Palm Research, Pedavegi-534 450, India \\ *Corresponding Author Email : anita.pedapati@gmail.com
}

\section{Abstract}

Aim: The present study was conducted to evaluate oil palm dura progenies developed from Zambia and Cameroon germplasm sources for bunch components for the selecting of high oil yielding mother palms.

Methodology: Total 77 dura genotypes were evaluated by considering 15 different bunch components. Bunch analysis data were collected from tenth year onwards after planting. The genetic diversity, Principal component analysis, correlation and path analysis of the genotypes were estimated.

Results: Study revealed that oil-to bunch ratio depends on fruit-to-bunch ratio and mesocarpfruit ratio. The ANOVA value showed a significant variability among the genotypes for most of the bunch traits and the identified genotype P35 $(24.53 \%)$ was highest oil yielder. Positive significant correlation $(p \leq 0.01)$ of mesocarp-tofruit ratio and oil-to-dry mesocarp with oil-tobunch ratio were noted in this study. Based on path analysis, the information obtained from this study is the oil-to-wet mesocarp ratio $(0.697)$ showed the highest significant positive direct effect on oil-to-bunch ratio followed by mesocarpto-fruit ratio (0.570).

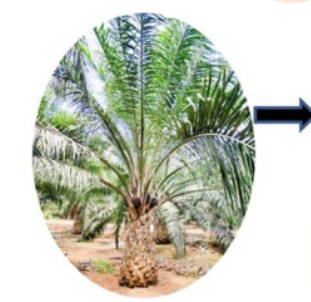

This study may support for the future selection of mother palms to utilize in oil palm improvement to utilize in oil palm imp
programmes

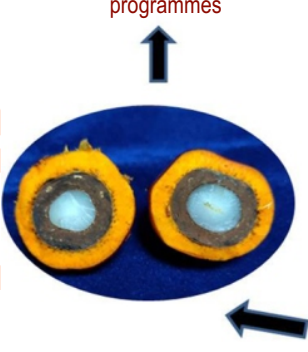

Positive significant correlation of mesocarp-to-fruit ratio and oil-to-dry mesocarp with oil-to-bunch ratio were showed in this study-

Evaluation of oil palm dura genotypes for bunch components

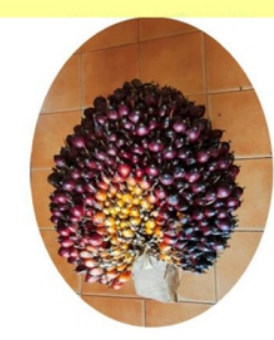

Sinificant variability among the genotypes for most of the bunch traits and identified genotype P35
$(24.53)$ is a highest oil yielder

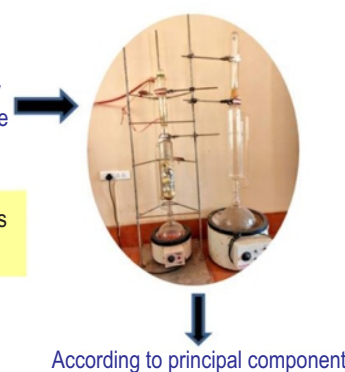

According to principal component analysi, the highest loadings for $\mathrm{PCl}$ came from oil-to-bunch ratio, weight of oil per sample, oil-to-dry mesocarp ratio and oil-to-wet mesocarp ratio-

Based on path analysis the oil-to-wet mesocarp ratio $(0.697)$ had the highest positive direct effect on oil-to-bunch ratio followed by mesocarp-to-fruit ratio $(0.570)$

Interpretation: This study may support for the future selection of mother palms to utilize in oil palm improvement programmes. Introgression into existing breeding materials and breeding for seed production utilising selected palms.

Key words: Bunch analysis, Dura, Mesocarp content, Oil palm

How to cite : Pedapati, A., R.K. Mathur, G. Ravichandran, B.K. Babu and H.P. Bhagya: Evaluation of bunch quality components in Dura x Dura progenies of Zambia and Camaroon sources of oil palm germplasm. J. Environ. Biol., 42, 1567-1577 (2021). 


\section{Introduction}

Oil palm (Elaeis guineensis Jacq.) a perennial oil yielding crop, belongs to the family Arecaceae. The oil palm is allogamous with diplod number of chromosomes $(2 n=32)$, It is a monoecious crop with inflorescences developing in the axils of almost every leaf. Oil palm is the highest productive oil crop and this alone meets the demand of global vegetable oils, that is estimated to reach 240 million tons by 2050 (Corley, 2009; Barcelos et al., 2015). Worldwide commercial grown oil palm has its origin from West Africa and oil palm trees grow upto $15-18 \mathrm{~m}$ in height. Fruits are arranged in large bunches in different layers and mature in 5-6 months after pollination. Each palm show great variation in fruit shape and size (Corley and Tinker, 2015). Oil palm is classified into three types of palms based on its fruit types, thick shelled dura, shell less pisifera and thin shelled tenera which is a cross between dura and pisifera. Mainly two types of oils are extracted commercially from oil palm fruits, crude palm oil (CPO) from mesocarp and palm kernel oil (PKO) from kernel. Oil palm dura used as a mother palm having dominant genotype sh+sh+, carries fruits with a thick shell and thin mesocarp. Though India have more than one million ha oil palm cultivated area, still we are spending enormous amount of economy for palm oil imports.

The edible oil mostly used in processing industries is palm oil, all baked foods, chips, canned food are made from this oil (Goggin et al., 2018). Palm oil significantly affects both the economy and the everyday needs of millions of people around the world (Rivas et al., 2012). Due to high quality, productivity and low cost, it can supply the market demand with less planting area than other vegetable oils (Cadena et al., 2013). Due to low cost and its high melting point, palm oil considered as one of the best oils for deep frying and reuse of used palm oil. Palm oil consist wide range of vitamins like $A, D, E$ and $K$ and essential healthy fatty acids. Palm oil is much appraised as highly nutritive oil seed crop. According to Murugesan et al. (2020) there is a need to select new valuable and promising traits from African germplasm for hybridization to produce trait specific hybrid varieties. The palm oil fruit exocarp, mesocarp, endocarp (shell), and kernel are different parts of oil palm fruit (Corley and Tinker, 2015).

Commercially, mesocarp and kernel of oil palm fruit are the richest sources of oil. Very less studies on oil palm bunch components, previous studies mostly on oil content from the oil palm bunch. So, there is a need to identify and breed high oil content mother palms with high mesocarp and oil content. This study reveals the similarity between palms and relationship between them studied by using cluster analysis, principal component analysis, correlation and path analysis respectively. The existing germplasm having narrow genetic base, so there is an urgent need of collecting trait specific germplasm. The major gap of Indian oil palm genetic resources is lack of high oil content oil palm varieties. Based on evaluating bunch characters, identifying high oil content mother palm is the major objective of this study. Oil yielding in oil palm is a heritable trait, so there is a need to evaluate in different breeding cycles to improve genetically.

\section{Materials and Methods}

Plant material: A total of 100 progenies of oil palm dura $x$ dura (44 CD (ZS-1) X 435 CD (CA-12 and 60 CD X 62 CD (ZS-8 inter se cross) with each cross 50 palms were planted in 2009 at ICARIndian Institute of Oil Palm Research, Pedavegi, West Godavari, India. The parent dura material introduced from Zambia and Cameroon during 1995 were planted in field genebank at Pedavegi.

Bunch analysis procedure and observations: For the present study, data collections were carried out for bunch quality components from 2017-2019 and the average of three years data were used for statistical analysis. The following bunch quality components included number of spikelet (NS); number of sterile fruits (NSF); total number of fruits (TNF); fruit-to-bunch ratio (F/B); weight of oil per sample (WOS); mesocarp moisture content (MMC); mesocarp-to-fruit ratio (M/F); kernel-to-fruit ratio $(\mathrm{K} / \mathrm{F})$; shell-to-fruit ratio $(\mathrm{S} / \mathrm{F})$; moisture content of nuts (MCN); oil-to-dry mesocarp ratio(O/DM); oil-to-wet mesocarp ratio (O/WM); kernel oil-to-fruit ratio (KO/F); kernel oil-to-bunch $(\mathrm{KO} / \mathrm{B})$ and oil-to-bunch ratio $(\mathrm{O} / \mathrm{B})$.

Harvesting stage of bunches for oil estimation is crucial, since oil formation is maximum during the last two weeks of bunch maturity. At least three bunches per palm were harvested for bunch analysis. Bunches were weighed immediately after bringing to laboratory and the spikelets were separated from the peduncle. The fruits from inner and outer layers of bunch were separated and weighed. The random samples of $250 \mathrm{~g}$ were used for oil solvent extraction in Soxhlet apparatus. Both estimation of mesocarp and kernel oil was done separately by following the same methodology (Mandal and Kochu Babu, 2008). Based on fruit typing of palms, only 77 dura type palms were included in the analysis. Ripe fresh fruit bunches of 10 -year-old palms were harvested and brought to laboratory for further processing (Fig. 1).

Data analyses: Bunch analyses was repeated three times for all palms and the minimum, maximum, mean values standard deviation and coefficient of variations were recorded and used for statistical analysis by SPSS package. The box plots, cluster analysis, principal component analysis, scatter plots, diversity, correlation and path analysis were analyzed by PAST statistical software (Hammer et al., 2001).

\section{Results and Discussion}

Comparative analyses (ANOVA, $P<0.01$ ) of 77 oil palm dura genotypes and their bunch traits are shown in Box plots (Table 1 and Fig. 2). Large variability was observed for all bunch quality traits among the genotypes, as in number of spikelet (105$230)$; number of sterile fruits (0-370), total number of fruits (3202108), fruit-to-bunch ratio (0.54-0.78), weight of oil per sample (1.70-2.44); mesocarp moisture content (13.47-66.67), 

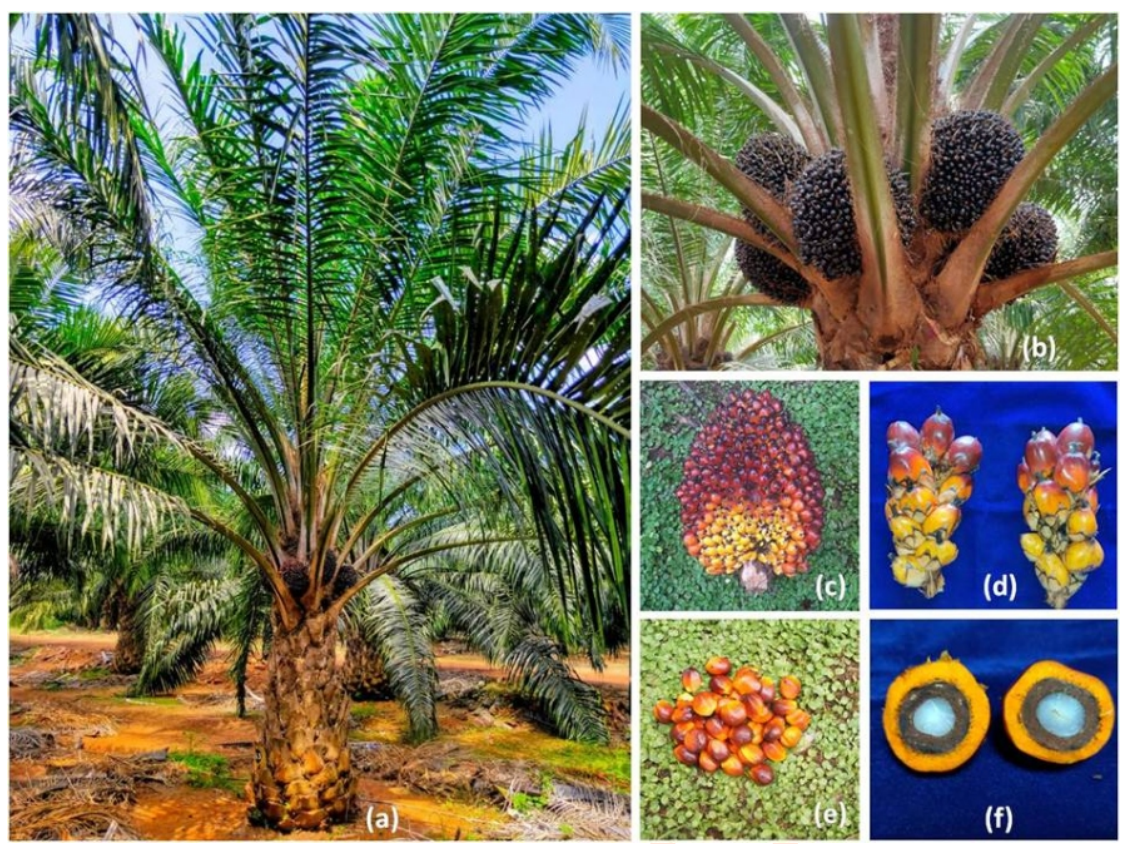

Fig.1: Selected Palm No. 35 (a) Palm; (b) Crown with bunches; (c) Ripen bunch; (d) Spikelets; (e) Fruits and (f) Thick shelled dura.
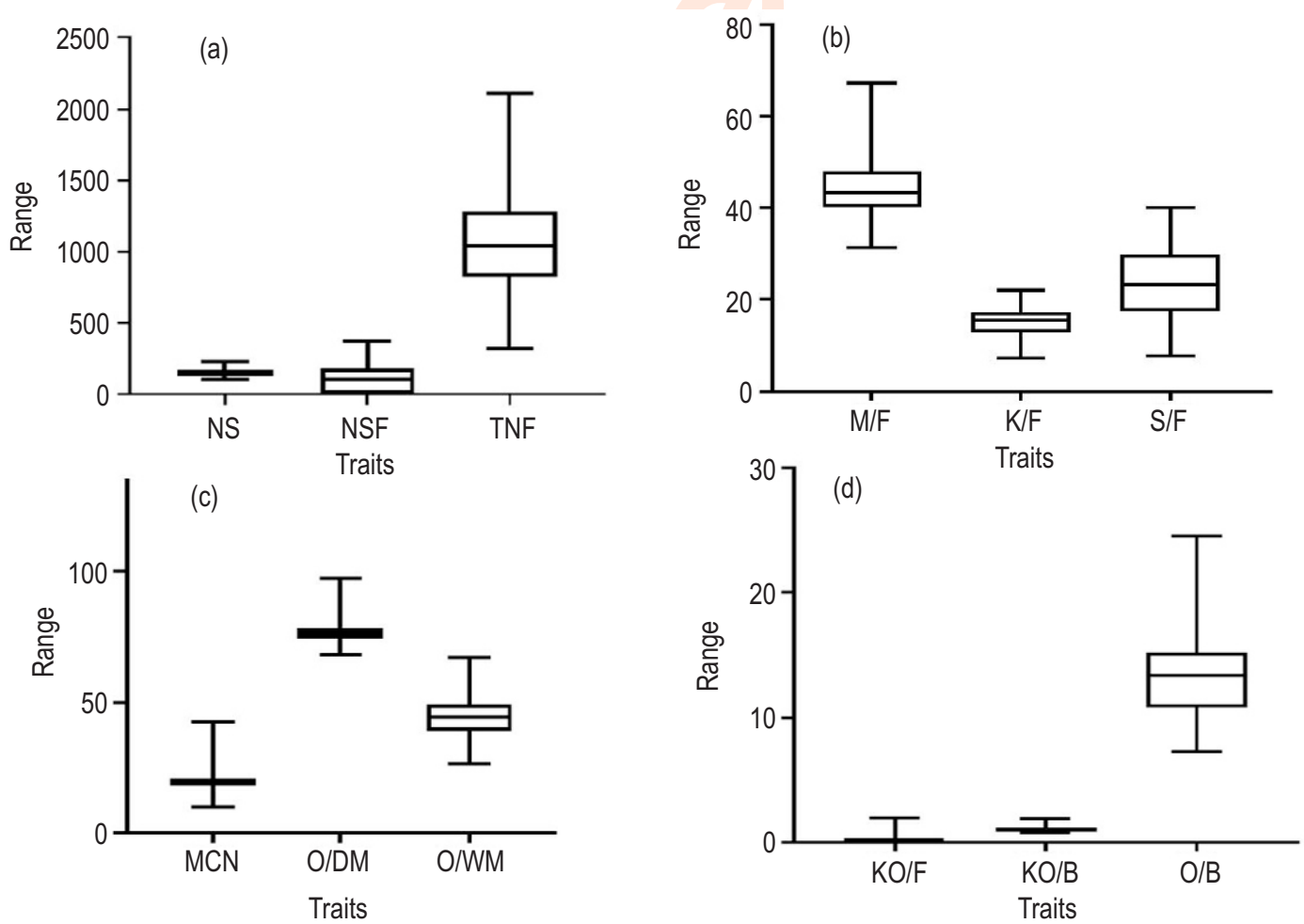

Fig. 2: Graph showing some of the box plots based on bunch component traits. X-axis represents number of spikelet (NS); number of sterile fruits (NSF); total number of fruits (TNF); mesocarp-to-fruit ratio (M/F); kernel-to-fruit ratio (K/F); shell-to-fruit ratio (S/F); moisture content of nuts (MCN); oil-to-dry mesocarp ratio (O/DM); oil-to-wet mesocarp ratio (O/WM); kernel oil-to-fruit ratio (KO/F); kernel oil-to-bunch (KO/B); oil-to-bunch ratio (O/B). 

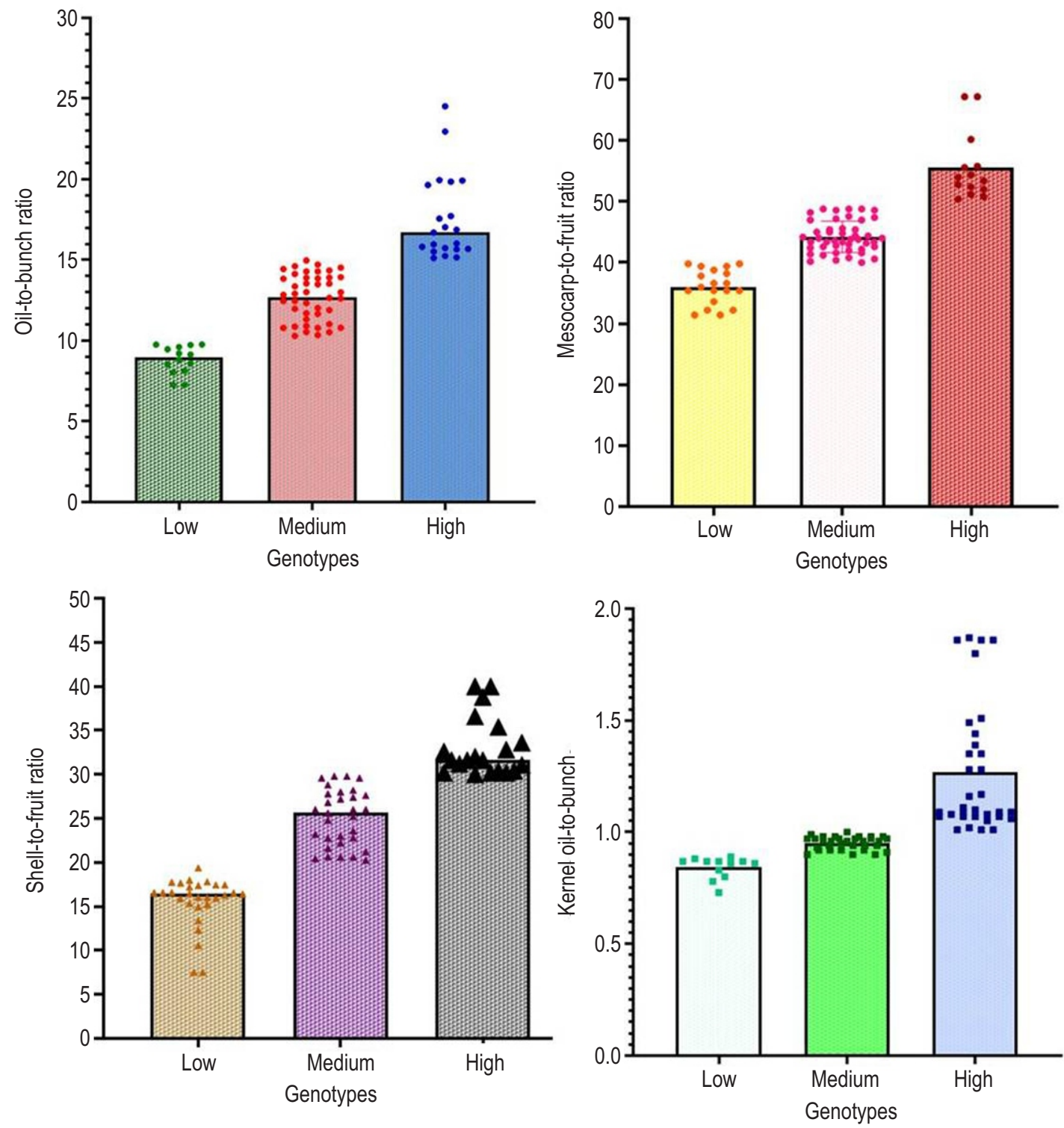

Fig.3: Total 77 dura genotypes are grouped into "low", "medium" and "high" for important traits like oil-to-bunch ratio, mesocarp-to-fruit ratio, shell-to-fruit ratio and oil-to-bunch.

mesocarp-to-fruit ratio (31.40-67.20), kernel-to-fruit ratio (7.2022.00), shell-to-fruit ratio (7.50-40.00), moisture content of nuts (10.20-42.75), oil-to-dry mesocarp ratio(67.93-97.47), oil-to-wet mesocarp ratio (26.31-67.31), kernel oil-to-fruit ratio (0.07-1.97), kernel oil-to-bunch (0.73-1.87), oil-to-bunch ratio (7.26-24.53). Among the 77 genotypes, P35 was identified as the highest oil yielding $(24.53 \%)$ and thin shelled $(7.50 \%)$ palm followed by P72 (22.96). Whereas, P77 was identified as the highest kernel oil-to-bunch $(1.87 \%)$ followed by P68. Kernel oil-to-fruit ratio showed the greatest CV (91.95) followed by number of sterile fruits (85.64), total number of fruits (32.67), shell-to-fruit ratio (30.05), oil-to-bunch ratio (25.40), kernel oil-to-bunch (24.11), kernel-to-fruit ratio (21.00), mesocarp moisture content (20.80), number of spikelet (20.11), moisture content of nuts (19.94), oilto-wet mesocarp ratio (17.27), mesocarp-to-fruit ratio (14.74), fruit-to-bunch ratio (8.19), weight of oil per sample (5.11), oil-todry mesocarp ratio (5.10). Total 77 dura genotypes were grouped into "low", "medium" and "high" for important traits were based on the range of standard values (Fig 3).

The group low for mesocarp-to-fruit ratio ranged from 31.4-39.8, medium group (40-48.8), high group (50.4-67.2). Fourteen genotypes are falls under high range, maximum genotypes are in medium range, very less low range genotypes 


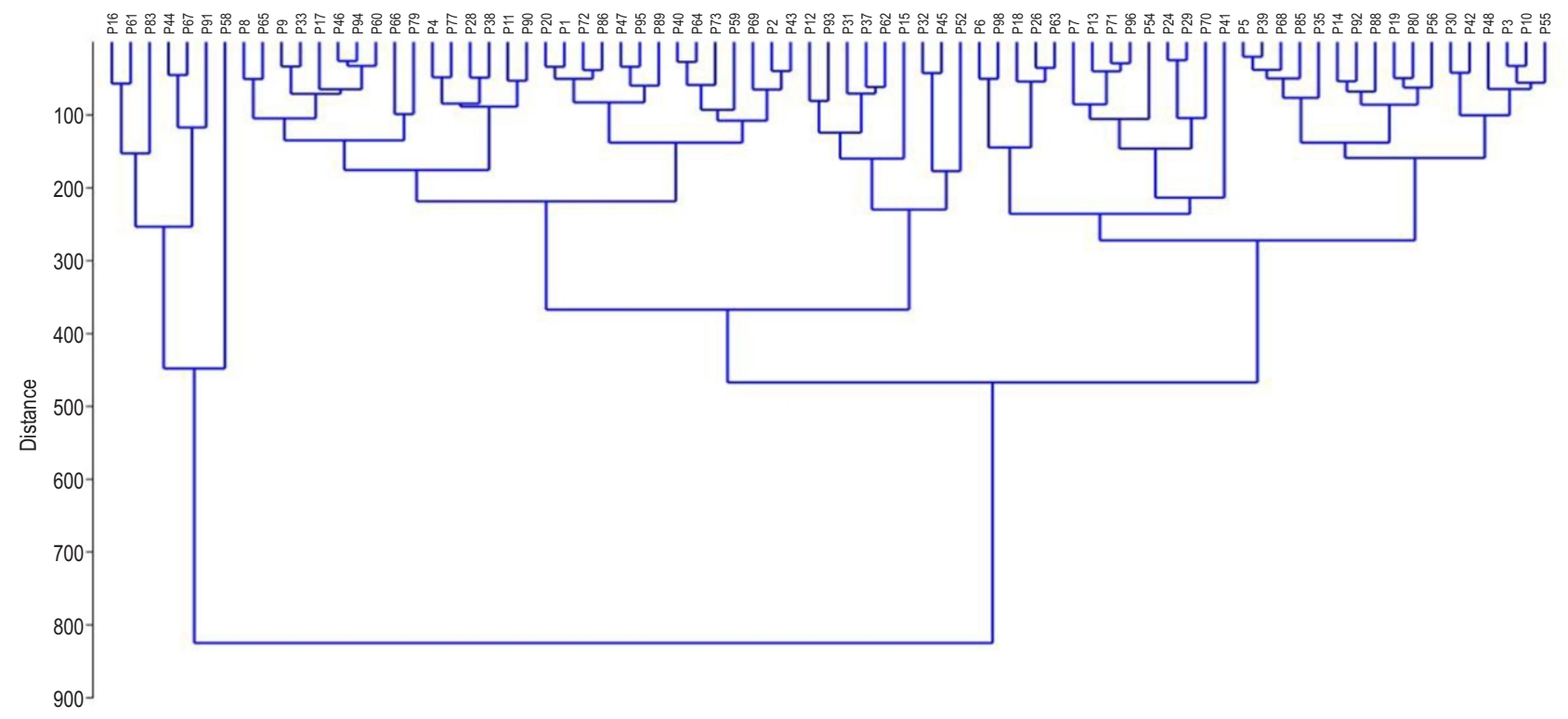

Fig 4: Dendrogram of 77 genotypes of dura oil palm based on bunch components traits.

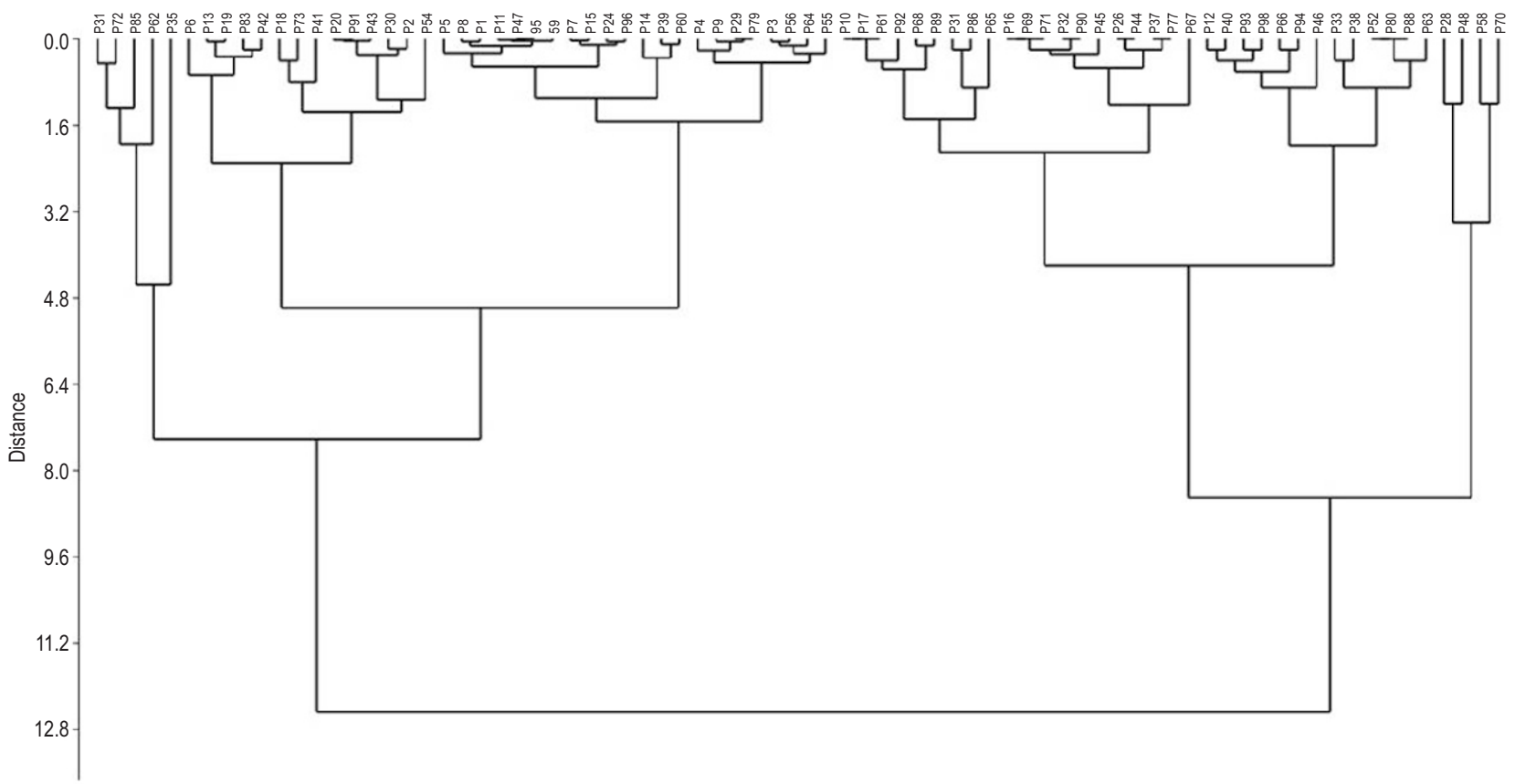

Fig 5: Dendrogram of 77 genotypes of dura oil palm based on shell thickness.

identified in this study for mesocarp-to-fruit ratio. The "low", "medium" and "high" for shell-to-fruit ratio of genotypes were 7.5$19.38,20.25-29.8,30-40$, respectively. For oil-to-bunch ratio, the range was $7.26-9.77,10.3-14.98,15.12-24.53$ whereas for kernel oil-to-bunch is in the order of $0.73-0.89,0.9-1,1.01-1.87$. The results revealed that the genotypes produced from Zambian (P35) and Camaroon (P72) parents were identified as the highest oil yielding $(24.53 \%, 22.96 \%)$ whereas the highest kernel oil was observed in genotypes produced from Cameroon source parent material. Low variability of bunch traits are more homogeneous 
and repeatable among the individuals, and therefore may be considered as stable traits (Khadivi et al., 2019). If the shell and kernel percentage increases, there would be a chance of reducing mesocarp content (Okoye et al., 2009). The present study showed that oil-to bunch ratio depends on fruit-to-bunch ratio, mesocarp-fruit ratio. The commercially important source of palm oil is from mesocarp and kernel, which are rich sources of oil (Murugesan et al., 2020). Therefore, factors affecting these traits are rather very important in pre-breeding programmes (Owolarafe et al., 2007; Sapey et al., 2012).

Some studies have shown higher oil content in bunches with large fruits (Rajanaidu and Jalani, 1994). However, this study may support for the future selection of genotypes to utilize in oil palm improvement programmes. Characterization and grouping of genotypes are essential or identifying diversified genotypes that can be utilized in breeding programmes. The present study, reported that Zambian genotype had minimum shell thickness when compared with other genotypes. Similar findings like minimum shell thickness of Zambian accession is one of the important outcomes of Murugesan et al. (2015). The shellthickness gene has a clear commercial value, with the heterozygotes having at least $30 \%$ yield advantage over either homozygote (Rance et al., 2001). To find out and identify the association and structure within the genotypes cluster analysis is a useful tool. Based on the genetic similarity of genotypes six clusters were formed as shown in dendrogram (Fig. 4). Cluster I included 17 genotypes (P5, P39, P68, P85, P35, P14, P92, P88, P19, P80, P56, P30, P42, P48, P3, P10, P55) with maximum oilto-wet mesocarp (46.43\%), among which ten genotypes were from same parents (Table 2). Cluster II had 14 genotypes (P6, P98, P18, P26, P63, P7, P13, P71, P96, P54, P24, P29, P70, P41) among which eight genotypes had common parents. Cluster III comprised nine genotypes (P12, P93, P31, P37, P62, $\mathrm{P} 15, \mathrm{P} 32, \mathrm{P} 45, \mathrm{P} 52)$ with less number of sterile fruits $(58.00)$ and high fruit-to-bunch ratio (0.71), weight of oil per sample (1.97), mesocarp-to-fruit ratio (48.71), kernel-to-fruit ratio (12.00), moisture content of nuts (17.40), oil-to-dry mesocarp ratio (78.82), kernel oil-to-fruit ratio (0.50), kernel oil-to-bunch (1.21) and oil-to-bunch ratio (15.48).

Only six genotypes had same common parents in Cluster III. Cluster IV having 14 genotypes (P20, P1, P72, P86, P47, P95, P89, P40, P64, P73, P59, P69, P2, P43) with more number of sterile fruits (168.07). Among Cluster IV, eight genotypes having Cameroon source parent material. Cluster $\mathrm{V}$ included 16 genotypes (P8, P65, P9, P33, P17, P46, P94, P60, P66, P79, P4, P77, P28, P38, P11, P90) with maximum genotypes from Zambian source parent material. The last Clusters $V$ had seven genotypes (P16, P61, P83, P44, P67, P91, P58) more number of fruits (1811.86), except one genotype remaining all are Cameroon source parent material where as the P16 is from Zambia. Fig. 5 shows six different clusters for single trait (shell thickness). Shell thickness is an important trait for mother palm selection. In the present study, oil palm dura genotypes with highest genetic distance between them were in different clusters while those with the least genetic distances belonged to same clusters (Rahman and Al-Mansur, 2009). Higher inter and intra cluster distances indicate higher genetic variability between and within clusters white the minimum inter and intra cluster distances indicate closeness among the genotypes of two clusters and within the clusters. On the other hand, crossing between populations with the least genetic distance between them should be avoided (Odewale et al., 2012), however, genotypes with minimum distance between them could be used for backcross breeding program (Mohammadi et al., 2003, Odewale et al., 2012. Rahim et al. (2010). Wang et al., 2021). Finally, it could be inferred cluster analysis that dura genotypes which are of same parentage are closer in relation.

Principal component analysis indicated that 15 traits were required to explain $100 \%$ of variation present in the oil palm dura genotypes. However, only first six principal components which accounted for $83.75 \%$ of total variation had eigen value greater than one and only PC1 and PC2 appeared to be the most useful as they described mostly oil and oil related traits variation. The first PC explained that $29.80 \%$ of the variation was positively correlated with fruit-to-bunch ratio, weight of oil per sample, mesocarp-to-fruit ratio, shell-to-fruit ratio, oil-to-dry mesocarp ratio, oil-to-wet mesocarp ratio, kernel oil-to-fruit ratio, kernel oilto-bunch, oil-to-bunch ratio. The second accounted for $17.39 \%$, which gave a cumulative value of $47.20 \%$. The highest loadings for PC1 came from oil-to-bunch ratio, weight of oil per sample, oilto-dry mesocarp ratio and oil-to-wet mesocarp ratio. Discrimination of oil palm dura genotypes based on its fruit and oil related traits was observed when genotypes were projected on two-dimensional graphs formed by PC1 and PC2, (Fig. 4).

After analyzing simple 77 genotypes, simple correlation between the bunch and oil related traits showed both positive and negative correlation (Table 3). The number of spikelets was positively significant with total number of fruits $(P \leq 0.01)$, the number of sterile fruits were positively and highly significant with kernel-to-fruit ratio. In addition, the total number of fruits were positively significant with kernel-to-fruit ratio. Similarly, fruit-tobunch ratio was positively highly significant $(P \leq 0.01)$ with kernel oil-to-fruit ratio and oil-to-bunch ratio. The weight of oil per sample was positively significant $(P \leq 0.01)$ with mesocarp-to-fruit ratio, oil-to-dry mesocarp ratio, oil-to-wet mesocarp ratio, kernel oil-tofruit ratio, kernel oil-to-bunch and oil-to-bunch ratio.

Mesocarp moisture content was positively significant with moisture content of nuts. Mesocarp-to-fruit ratio was positively significant $(P \leq 0.01)$ with oil-to-dry mesocarp ratio and oil-to-bunch ratio. Oil-to-dry mesocarp ratio was positively and highly significant with oil-to-wet mesocarp ratio, kernel oilto-fruit ratio, kernel oil-to-bunch and oil-to-bunch ratio. Kernel oil-to-bunch was positively and highly significant with kernel oilto-bunch. The existence of close positive correlations among fruit-to-bunch ratio, weight of oil per sample, mesocarp-to-fruit ratio, oil-to-dry mesocarp ratio, oil-to-wet mesocarp ratios 

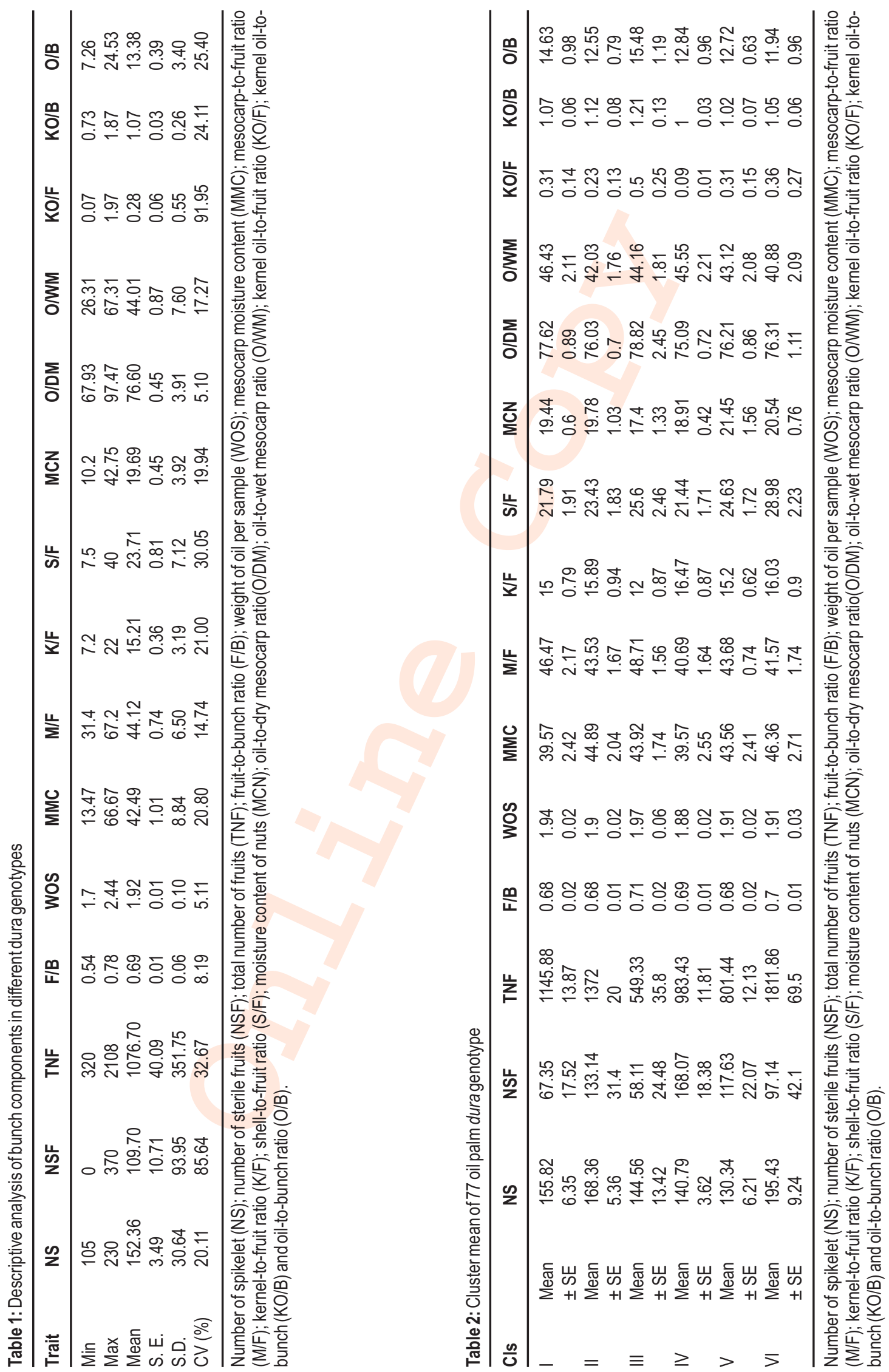

- Journal of Environmental Biology, November 2021 • 


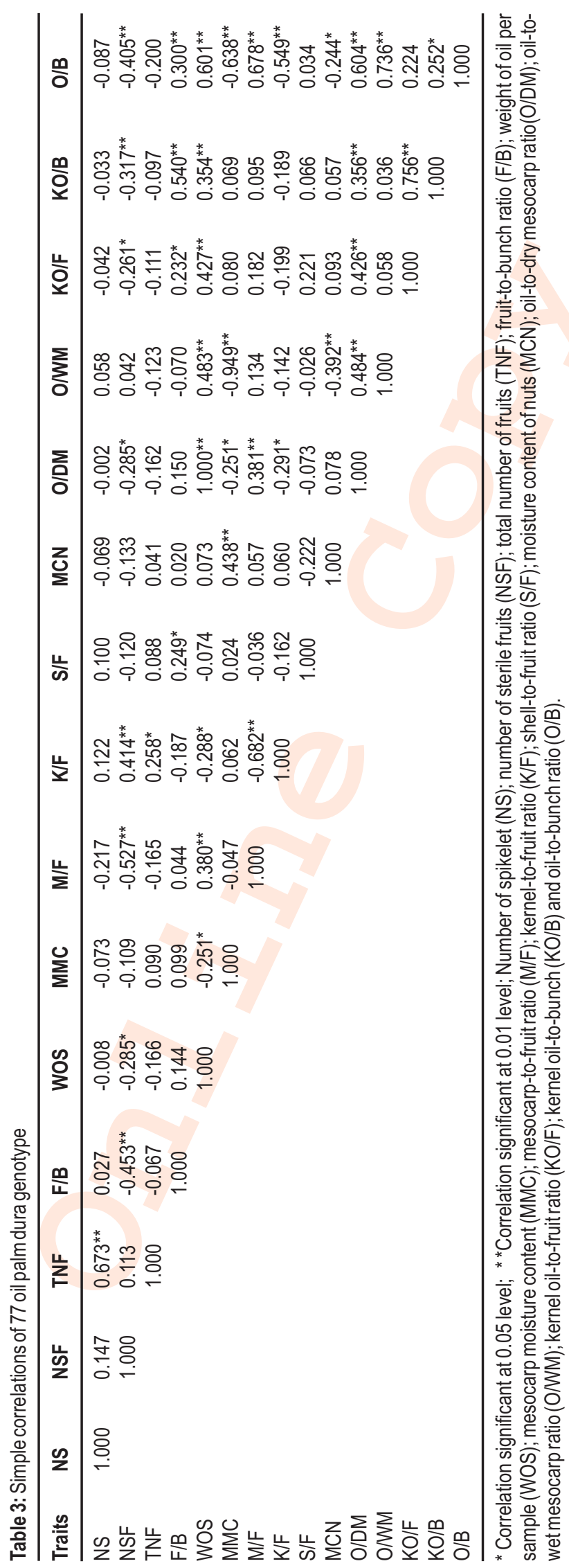

- Journal of Environmental Biology, November 2021 • 


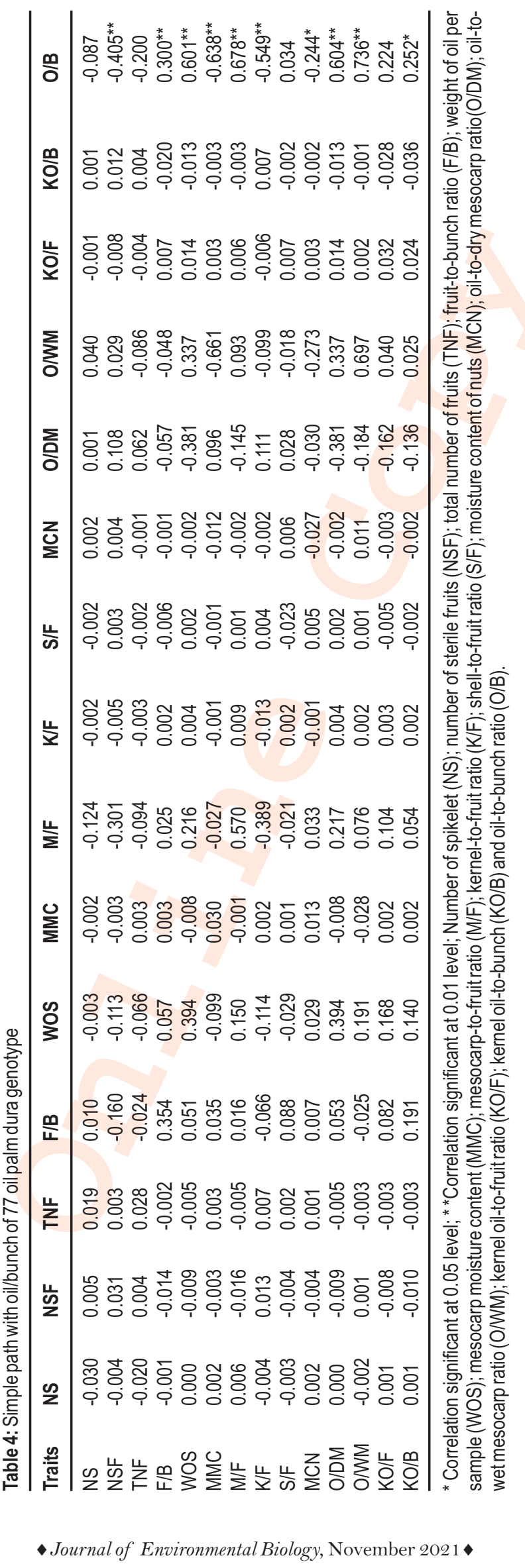


showed a highly significant positive correlation with oil-tobunch ratio. While oil-to-bunch ratio was negatively and significantly correlated with number of sterile fruits, mesocarp moisture content, kernel-to-fruit ratio and moisture content of nuts. The positive significant correlation of mesocarp-to-fruit ratio with oil-to-dry mesocarp and oil-to-bunch indicates the influence of these traits on bunch oil content. These results are in agreement with the previous findings of Kushairi et al. (1999), Okoye et al. (2009) and Krualee et al. (2013).

While negatively significantly correlated oil-to-bunch ratio with number of sterile fruits, mesocarp moisture content, kernel-to-fruit ratio and moisture content of nuts. This negative correlation advocates that oil-to-bunch ratio is negatively influenced by these traits. Based on the present result it may be concluded that these variables can be utilized in breeding programmes (Khadivi-Khub et al., 2015). By using path analysis, the direct and indirect effects of various bunch traits on oil-to-bunch ratio were estimated (Table 4). The results showed that oil-to-wet mesocarp ratio $(0.697)$ had the highest positive direct effect on oil-to-bunch ratio followed by mesocarp-to-fruit ratio (0.570). The direct effect of number of sterile fruits and total number of fruits was negligible. Important oil deciding bunch traits like kernel-to-fruit ratio, shell-to-fruit ratio, oil-to-dry mesocarp ratio had a negative direct effect on oil-tobunch ratio. Furthermore, the negligible negative direct effect of kernel-to-fruit ratio $(-0.013)$ and shell-to-fruit ratio $(-0.023)$ on oilto-bunch ratio were also observed in this study.

The direct and indirect effects of various bunch traits on oil-to-bunch ratio results are in agreement with the previous findings of (Krualee et al. (2013) who reported that oil-to-wet mesocarp ratio has a direct effect on oil yield per palm and also has an effect on the percentage of oil per bunch, which plays a major role in increasing oil yield. One of the major economic value among the bunch quality components is oil-to-wet mesocarp ratio which correlates with the correct stage of fruit ripening. The important oil deciding bunch traits like kernel-to-fruit ratio, shellto-fruit ratio, and oil-to-dry mesocarp ratio had a negative direct effect on oil-to-bunch ratio may be having different genetic background. Similar findings were observed by Peng et al. (2019) who reported that kernel and shell have indirect effect on oil-tobunch ratio. They also evaluated correlations and path analysis in oil palm and clearly concluded that if the fresh mesocarp per fruit and fruit per bunch were improved, the oil yield might be increased (Okoye et al., 2007; Krualee et al., 2013) due to its less shell and kernel content. Based on this study, the palms selected may be utilized for further hybridization programme in hybrid seed production after necessary evaluation before crossing of palms (Bhagya et al., 2020).

To conclude, this study examined 77 oil palm dura genotypes for bunch components to understand the variations. Higher levels of mesocarp and oil-to-dry mesocarp may lead to higher oil content. The most important outcome of the present study is kernel oil which is also as important as mesocarp oil, therefore, breeder should focus on kernel quality improvement. The selected palm which has high oil to bunch ratio may be used in breeding programmes.

\section{Acknowledgments}

We acknowledge the Director of ICAR-Indian Institute of Oil Palm Research and for providing research facilities and their support.

\section{Add-on Information}

Authors' contribution: A. Pedapati: Main author, Complete analysis; R.K. Mathur: Correction and suggestions; G. Ravichandran: Maintanance of mother palms; B.K. Babu: Corrections; H.P. Bhagya: Statastical analysis.

Research content: The research content of the manuscript is original and not published elsewhere.

Ethical approval: NotApplicable.

Conflict of interest: The authors declare that there is no conflict of interest.

Data from other sources: NotApplicable.

Consent to publish: All authors agree to publish the paper in Journal of Environmental Biology.

\section{References}

Akinoso, R. and A.O. Raji: Physical properties of fruit, nut and kernel of oil palm. Int. Agrophys., 25, 85-88 (2010).

Barcelos, E., S.D.A. Rios, R.N.V. Cunha, R. Lopes, S.Y. Motoike, E. Babiychuk, A. Skirycz and S. Kushnir: Oil palm natural diversity and the potential for yield improvement. Front. Plant Sci., 6, 190 (2015).

Bhagya, H.P., B. Kalyana Babu, P. M. Gangadharappa, Mahantesha B. N. Naika, D. Satish and R. K. Mathur: Identification of QTLs in oil palm (Elaeis guineensis Jacq.) using SSR markers through association mapping. J. Gene., 99,1-10 (2020).

Blaak, G., L.D. Sparnaaij and T. Menendez: Breeding and inheritance in the oil palm (Elaeis guineensis Jacq.). II. Methods of bunch quality analysis. J. WestAfrican Inst. Oil Palm Res., 4, 146-155 (1963).

Cadena, T., F. Prada, A. Perea and H.M. Romero: Lipase activity, mesopcarp oil content, and iodine values in oil palm fruits of Elaeis guineensis, Elaeis oleifera and the interspecific hybrid $O \times G(E$. oleiferax E. guineensis). J. Sci. Food Agric., 93, 674-680 (2013).

Corley, R.H.V.: How much palm oil do we need? Environ. Sci. Policy., 12, 134-139 (2009).

Corley, R.H.V. and P.B. Tinker: The Oil Palm. $5^{\text {th }}$ Edn., Blackwell Publishing, Oxford, Berlin, Germany (2015).

Goggin, K.A. and D.J. Murphy: Monitoring the traceability, safety and authenticity of imported palm oils in Europe. Oilseeds fats, Crop. Lipid., 25, A603 (2018).

Hammer, O., D.A.T. Harper and P.D. Ryan: Past: Paleontological statistics software package for education and data analysis. Paleontol. Electron., 4, 1-9 (2001).

Harun, M.H., M. Roslan and M.D. Noor: Fruit set and oil palm bunch 
components. J. Oil Palm Res., 14, 24-33 (2002).

Khadivi, A., L. Safdari, M.H. Hajian and F. Safari: Selection of the promising almond (Prunus amygdalus L.) genotypes among seedling origin trees. Sci. Hortic., 256,108587 (2019).

Khadivi-Khub, A., S. Karimi and M. Kameli: Morphological diversity of naturally grown Crataegus monogyna (Rosaceae, Maloideae) in Central Iran. Braz. J. Bot., 38, 921-936 (2015).

Krualee, S., S. Sdoodee, T. Eksomtramage and V. Sereeprasert: Correlation and path analysis of palm oil yield components in oil palm (Elaeis guineensis Jacq.). Kasetsart J. Nat. Sci., 47, 528-533 (2013)

Kushairi A. N. Rajanaidu, B.S. Jaiani and Z.A. Isa: PORIM Series 1PORIM Elite Oil Palm Planting Materials. PORIM Info. Ser. No. 100. PORIM, Bangi (1999).

Mandal P.K. and M. Kochu Babu: Bunch analysis of oil palm. Technical Bulletin, No.8. (Published by Kochu Babu, M., Director, November, 2008). National Research Centre on Oil Palm, Pedavegi, Andhra Pradesh (2008).

Mohammadi, S.A. and B.M. Prassana: Analysis of genetic diversity in crop plants-salient statistical tools and considerations. Crop Sci., 43, 1235-1248 (2003)

Murugesan, P., K.L.M. Rani, P.N. Kumar, D. Ramajayam, K.S. Kumar, R.K. Mathur, G. Ravichandran and V. Arunachalam: Genetic diversity of vegetative and bunch traits of African oil palm (Elaeis guineensis) germplasm in India. Indian J. Agricult. Sci., 85, 892$895(2015)$

Murugesan, P., D. Ramajayam, P.N. Kumar, A. Pedapati, G. Ravichandran, H.P. Bhagya and V. Pandey: Evaluation of wild oil palm germplasm for horticultural traits. Indian J. Hort., 77, 406-411 (2020).

Odewale, J.O., A.Collins, C.D. Ataga, N.O.Aisueni, C.E.lkuenobe, M.N.Okoye, G. Odiowaya, A.A. Edpkpayi, M.J. Ahanor and E.O. Uwadiae: Pattern of genetic diversity and variability in germplasm resources of local and exotic coconut (Cocos nucifera L.) cultivars in Nigeria. J. Agricul. Sci., 2, 202-207 (2012).

Okoye, M., C. Okwuagwu and M. Uguru: Population improvement for fresh fruit bunch yield and yield components in oil palm (Elaeis guineensis Jacq.) Amer. Eurasian J. Sci. Res., 4, 59-63 (2009).

Owolarafe, O., M. Olabige and M. Faborode: Physical and mechanical properties of two varieties of fresh oil palm fruit. J. Food Eng., 78, 1228-1232 (2007).

Patcharin, T., H. Yaowanat, T Puntaree and P. Srinives: Estimates of repeatability and path coefficient of bunch and fruit traits in Bang Boet dura oil palm. J. Oil Palm Res., 25, 108-115 (2013).

Peng, S., Y. Wang, D. Zhang and Y.M. Htwe: Hainan and Leonard Osayande Ihase: Analysis on fruit oil content and evaluation on germplasm in oil palm. Hort. Sci., 54, 1275-1279 (2019).

Rahman, M.M. and M.A.Z Al-Munsur: Genetic divergence analysis of lime. J. BangladeshAgric. Univ., 7, 33-37 (2009).

Rahim, M.A., A.A. Mia, F.Mahmud, N. Zeba and K. Afrin: Genetic variability, character association and genetic divergence in mungbean (Vigna radiate L. Wilczek). Plant Omic., 3, 1-6 (2010).

Rajanaidu, N. and B.S. Jalani: Prospects for breeding for kernels in oil palm (Elaeis guineensis). Planter, 70, 307-318 (1994).

Rance, K.A., S. Mayes, Z. Price, P.L. Jack and R.H.V. Corley: Quantitative trait loci for yield components in oil palm (Elaeis guineensis Jacq.). Theor. Appli. Gene., 103, 1302-1310 (2001).

Rivas, M., R.L. Barbieri and L.C. da Maia: Plant breeding and in-situ utilization of palm trees. Cienc. Rural, 42, 261-269 (2012).

Sapey, E., K. Adusei-Fosu, D. Agyei-Dwarko and G. Okyere-Boateng: Collection of oil palm (Elaeis guineensis Jacq.) germplasm in the northern regions of Ghana. Asian J. Agricul. Sci., 4, 325-328 (2012).

Wang, Y., J. Zhao, H. Chen, Q. Zhang, Y. Zheng and D. Li : Molecular cloning and characterization of long-chain acyl-CoA synthetase 9 from the mesocarp of African oil palm (Elaeis guineensis Jacq.). Sci. Horticul., 276, 1-9 (2021). 